\title{
Analisando a produção da família de pessoas com deficiência nos discursos das políticas de inclusão
}

\author{
Priscila Turchiello*
}

\section{Resumo}

A análise proposta neste texto busca problematizar a produção da família de pessoas com deficiência como alvo das políticas de inclusão na Contemporaneidade. Tomando como lentes teóricas os estudos pós-estruturalistas em educação e parcelas do pensamento de Michel Foucault, o estudo apresenta dois movimentos, primeiramente procura sinalizar como a família foi produzida como instituição voltada à vigilância da infância na esteira da Modernidade, criando condiçôes para a visualização na atualidade de investimentos que acabam posicionando-a como instrumento para a inclusão de pessoas com deficiência. Para dar conta da compreensão de como vai se produzindo certa aliança entre a família e a inclusão, elegeu-se como materialidade os documentos Educaçáo Inclusiva: a família (BRASIL, 2004) e A hora e a vez da família em uma sociedade inclusiva (BRASIL, 2006). Na discursividade analisada, a aliança entre família e inclusão propóe-se a gerenciar o risco da exclusão social e educacional das pessoas com deficiência.

Palavras-chave: Família de pessoas com deficiência; Discursos; Políticas de inclusão.

\footnotetext{
* Professora do Instituto Federal de Educaçáo, Ciência e Tecnologia Farroupilha - Contemplada com o Programa Institucional de Incentivo à Qualificação Profissional dos Servidores do Instituto Federal Farroupilha, Jaguari, Rio Grande do Sul, Brasil.
} 


\section{Analysing the production of families of disabled people in the discourse of inclusion policies}

\section{Abstract}

The proposed analysis in this text has as purpose to problematize the production of a family with disabilities as target of the inclusion policies in the Contemporaneity. Taking as theoretical lenses the post-structuralists investigations about education and parts of the ideas of Michel Foucault, the analysis presents two movements, firstly it intends to highlight how the family has been produced as institution aimed to the surveillance of the childhood in the environment of the Modernity, creating conditions for the visualization in the current times of efforts that eventually lead it to become an instrument for the inclusion of people with disabilities. For the sake of the comprehension of how the production of a certain alliance between the family and education happens were chosen as materials the documents: Educação Inclusiva: a família (Inclusive Education: the family) (BRASIL, 2004) and (A hora e a vez da família em uma sociedade inclusiva (BRASIL, 2006) (The time of the family in an inclusive society). In the analysed discourse, the alliance between the family and the inclusion proposes to manage the risk of the social and educational exclusion of the disabled people.

Keywords: Family of disabled people; Discourses, Inclusion policies.

A inclusão se constitui como um imperativo no contexto contemporâneo, sendo produzida discursivamente como uma verdade inquestionável e, assim, considerada necessária. Com força de lei, a inclusão vem buscando garantir a igualdade de condiçôes e o direito de participação das pessoas com deficiência nos espaços comuns da sociedade. Dessa maneira, diferentes discursos são articulados na produção de uma política de verdade que cria as condiçôes para que a inclusão seja tomada como lugar de chegada para todos.

Os discursos das políticas de inclusão são ativados por mecanismos de regulamentação da vida, na tentativa de controlar e gerenciar fatores de risco social, como uma forma de segurança da população. Foucault no curso Em defesa da Sociedade, possibilita pensar sobre essa questão, quando expóe que uma tecnologia centrada na vida, "agrupa os efeitos de massas próprios de uma população, que procura controlar a série de eventos fortuitos que podem ocorrer numa massa viva; uma tecnologia que procura controlar (eventualmente modificar) a probabilidade desses eventos" (FOUCAULT, 1999, p. 297).

Nessa racionalidade, as políticas de inclusão se constituem como uma medida biopolítica, investindo em diferentes estratégias que possibilitam prevenir a ocorrência de fatores de risco, bem como gerenciá-los. A produção do risco a partir da identificação estatística de alguns fatores ou condiçốes de risco - que, no caso da inclusão, estão relacionados à segregação, exclusão, baixa escolarização, analfabetismo, evasão escolar, falta de empregos, entre outros - é que acaba por solicitar tais estratégias 
como investimentos para maximizar a vida produtiva do coletivo populacional. Nas palavras de Foucault (1999), essa tecnologia, ou seja, a biopolítica:

[...] se dirige à multiplicidade dos homens, não na medida em que eles se resumem em corpos, mas na medida que ela forma, ao contrário, uma massa global, afetada por processos de conjunto que são próprios da vida, que são processos como o nascimento, a morte, a produção, a doença, etc. (FOUCAULT, 1999, p. 289).

Compreendendo que os grupos vulneráveis aos fatores de risco são aqueles produzidos como população alvo das ações do Estado, considero que as políticas de inclusão investem sobre as pessoas com deficiência, acionando diferentes instrumentos, entre eles, as famílias desses sujeitos, que são fabricadas como alvo e também agente das políticas de inclusão. Utilizo o termo "fabricação" porque entendo que o discurso "não descreve simplesmente os objetos que lhe são exteriores, o discurso 'fabrica' os objetos sobre os quais fala" (SILVA, 2000, p.43, grifos do autor), isto é, ao falarem sobre as famílias, os discursos das políticas de inclusão produzem determinadas verdades sobre elas.

Nessa racionalidade, a família é chamada a vigiar aqueles que vão, nessa conjuntura discursiva, sendo produzidos como sujeitos do risco. Com isso, estabelece-se certa "aliança" entre a família das pessoas com deficiência e a inclusão. Há um enlace entre a produção desses sujeitos como sujeitos de risco e a necessidade de vigilância da família, pois se pressupõe que, dentre as funções da família, está a de manter um olhar atento e ininterrupto sobre as açôes dos filhos. Bauman (2003, p.35), em suas análises, diz que "o dever dos pais é guiar e restringir, mas para realizá-lo de modo sério e responsável eles precisam antes de mais nada vigiar e supervisionar".

As políticas de inclusão vêm se constituir no contexto contemporâneo, seguindo uma ordem discursiva em que a seguridade da população se coloca como central, sendo assim engendradas açôes que buscam, através de um exercício de poder mais sutil, vigiar e minimizar o risco social, contemplando também nesse jogo a família de pessoas com deficiência.

Cabe considerar que a família, como vem sendo tratada nos discursos das políticas de inclusão, é tomada como uma instituição sempre existente, naturalizada. Para tanto, nesse texto, procuro inicialmente olhar para a instituição da família como parceira de vigilância numa racionalidade moderna, para na sequência apresentar as recorrências discursivas que instituem a família como uma ferramenta no processo de inclusão do filho com deficiência, ao analisar o conjunto de enunciados dos materiais Educação Inclusiva: a família (BRASIL, 2004) e A hora e a vez da família em uma sociedade inclusiva (BRASIL, 2006).

Dentre as diversas formas de olhar para a temática deste texto, elejo os estudos de vertente pós-estruturalista em educação e parcelas do pensamento de Michel Foucault como lentes para considerar os discursos recorrentes nos materiais, isso porque essa perspectiva teórica me permite analisar não o que são as políticas de inclusão e a família, mas como elas vêm sendo produzidas, fabricadas. O que proponho está relacionado a um comprometimento com a desnaturalizaçáo de verdades a partir da 
análise de como foram sendo produzidos os ditos sobre a família, possibilitando perceber, na discursividade dos documentos, a família de pessoas com deficiência sendo produzida num exercício de poder-saber que institui formas particulares de narrá-la, tomadas como verdadeiras.

\section{A função vigilante da família no registro da ordem moderna}

Em Foucault (2001) e Donzelot (2001), podemos encontrar referência à crescente preocupação com as crianças no decorrer do século XVIII, o que se constitui como condição de possibilidade para a produção de discursos sobre o papel das famílias. A organização familiar típica do Antigo Regime, em que as relaçôes de dependência, ascendência e descendência acabavam por configurar a família como a menor organização política possível, acabou sofrendo modificaçôes, tendo em vista a necessidade de "reorganização dos comportamentos educativos" (DONZELOT, 2001, p.21). Essa questão torna-se significativa para este estudo porque entendo que, para essa reorganização desenvolver-se, se coloca como necessidade a reestruturação do espaço familiar, inscrevendo-se a família num exercício de vigilância contínua de todos aqueles que nela circulam.

Nesse cenário é que vamos perceber a configuração de estratégias que investem sobre as famílias na busca de novas condiçóes de educação para seus filhos. Essas estratégias organizam-se a partir de dois eixos distintos, definidos por Donzelot (2001, p.21-22) como "medicina doméstica" e "economia social", que têm como alvo de suas açôes a família burguesa e a família popular, respectivamente.

A instauração do médico de família no contexto burguês apresenta como principal objetivo a constituição de um ambiente familiar em que os pais busquem se responsabilizar pelo cuidado dos filhos. As famílias são aconselhadas pela medicina a reestruturar o espaço da casa, mantendo os filhos sob vigilância e afastando-os das influências dos serviçais, que comumente assumem a função do cuidado das crianças. Dessa maneira, exige-se uma reorganização do espaço familiar para que se torne um espaço de vigilância ininterrupta (FOUCAULT, 2001).

De acordo com Donzelot (2001, p.23-24), a ligação do médico com a família, no século XVIII, repercutirá profundamente na reorganização familiar nas seguintes direçôes:

1. o fechamento da família contra as influências negativas do antigo meio educativo, contra os métodos e os preconceitos dos serviçais, contra todos os efeitos das promiscuidades sociais; 2. a constituição de uma aliança privilegiada com a mãe, portadora de uma promoção da mulher por causa deste reconhecimento de sua utilidade educativa; 3 . a utilização da família pelo médico contra as antigas estruturas de ensino, a disciplina religiosa, o hábito do internato.

A constituição desse novo corpo familiar a partir da intervenção médica configura o que Foucault (2001) chama de "família-célula", em que as relaçóes entre pais e filhos se tornam mais próximas, havendo um envolvimento do corpo dos pais com 
os dos filhos, buscando-se eliminar os intermediários. Dá-se o fechamento da família - uma pequena família sólida, corporal e afetiva que mantém o corpo das crianças sob controle e vigilância.

No caso das famílias de pessoas com deficiência, penso que a disciplina médica também contribuirá para a aproximação entre os pais e seus filhos deficientes. A narrativa histórica sobre as formas de se relacionar com os sujeitos deficientes na sociedade e no interior das famílias permite-nos compreender que, em diferentes momentos, essas relaçóes se deram priorizando o afastamento dos deficientes do convívio social e familiar ${ }^{1}$.

Diferentes discursos posicionam as famílias como responsáveis e, muitas vezes, culpadas pelas deficiências de seus filhos. Com isso, a presença de filhos com deficiência expóe as famílias a uma situação vergonhosa no âmbito social, o que leva a certo abandono por parte dos pais, tanto dos cuidados quanto da convivência com esses sujeitos, delegando-os muitas vezes a preceptores, serviçais, entre outros.

Cabe observar que as açôes empreendidas pela ordem médica não se voltam a qualquer tipo de família, mas sim a uma família burguesa, que apresentava condiçóes de manter em seu meio os intermediários. Sendo assim, o investimento sobre a família popular vai se dar respondendo a uma outra ordem, isto é, não está direcionado ao afastamento dos serviçais e à aproximação do corpo dos pais e dos filhos, mas a uma campanha "contra a união livre, contra o concubinato, contra a fluidez extra ou para-familiar” (FOUCAULT, 2001, p.342).

Donzelot (2001) considera que, nas famílias populares, também se tem como foco a preocupação com a infância; no entanto, as ações configuram-se nesse espaço de forma diferenciada, pois os problemas dessas famílias são diferentes daqueles que eram percebidos nas famílias burguesas. A produção de discursos higiênicos no contexto popular encontra na "economia social" a possibilidade de investir sobre as famílias buscando:

[...] entravar liberdades assumidas (abandono de crianças em hospícios para menores, abandono disfarçado em nutrizes), [...] controlar as uniốes livres (desenvolvimento do concubinato com a urbanização na primeira metade do século XIX), [...] impedir linhas de fuga (vagabundagem dos indivíduos, particularmente das crianças). Em tudo isso náo se trata mais de assegurar proteçóes discretas, mas sim de estabelecer vigilâncias diretas (DONZELOT, 2001, p.27).

Para efetivar essa reorganização da família popular, tendo como centrais as questóes econômicas e sociais, diferentes espaços, como os hospitais gerais, conventos e hospícios, virão a se constituir como observatórios das condutas, servindo então de apoio para toda uma série de intervençóes na vida familiar (DONZELOT, 2001). Penso que esses espaços serviram amplamente às famílias de pessoas com deficiência, no sentido de eximi-las da responsabilidade de cuidado dos filhos deficientes, já que, diferentemente da família burguesa, as famílias populares não tinham condiçôes de manter serviçais e empregados a seu dispor. 
Contudo, a percepção de que o acolhimento dos menores em espaços como os hospitais e hospícios estava se ampliando de forma desmedida levou os órgáos de administração do final do século XVIII a analisar as problemáticas envolvidas na organização desses espaços. Então, no início do século XIX, cria-se o salário-família, destinado às famílias populares, com o objetivo de possibilitar a atuação do médico sobre as crianças, além de um apoio financeiro (DONZELOT, 2001). Essa preocupação com a organização e controle econômico e político da classe proletária provoca um investimento na consolidaçáo do matrimônio e, consequentemente, na constituição de um espaço familiar internamente organizado (FOUCAULT, 2001), diminuindo-se dessa forma os custos do Estado com a assistência às famílias populares.

A Modernidade se ocupou da organização familiar burguesa e popular no intuito de mantê-la sob uma ordem social que buscava maximizar as forças de seus membros, dotando as famílias de mecanismos de vigilância e controle sobre as crianças. A produção de discursos, especialmente médicos, higienistas e assistenciais, sobre a preservação da infância e a função familiar possibilitou a emergência da família vigilante no contexto moderno. Há uma valorização da família, que acaba por voltar-se a si mesma no intuito de preservar a vida.

Entendo que essa família vigilante, típica do contexto moderno, vem a constituir-se como uma ferramenta para a ingerência dos sujeitos deficientes. Na busca pela produção de saberes sobre esses sujeitos, as famílias de pessoas com deficiência também passam a desempenhar funçôes diferenciadas que atentam para o controle e vigilância dos comportamentos, hábitos e atitudes dos filhos num contexto restrito. As famílias de pessoas com deficiência precisam reorganizar-se para atender aos novos comportamentos educativos engendrados na Modernidade, o que exige uma aproximação com os filhos deficientes, responsabilizando-se por seu cuidado e desenvolvimento.

Os atuais discursos da inclusão continuam enunciando a necessidade de que as famílias assumam seu papel educativo, possibilitando o direcionamento de uma nova vida para seus filhos deficientes, agora em contextos inclusivos. O que permite pensar na fabricação dessa família por esses discursos, atendendo a uma aliança família/ inclusão que produz sujeitos normalizados, vigiados e úteis à ordem contemporânea.

\section{Investimento das políticas de inclusão na família de pessoas com deficiência}

A partir da perspectiva teórica em que este estudo se filia, os discursos das políticas de inclusão são tomados como produtores de significados sobre a inclusáo e a família de pessoas com deficiência, e não como um conjunto de signos ou, nas palavras de Foucault (2008, p.54), "um puro e simples entrecruzamento de coisas e de palavras" que representam os objetos e o mundo. Os discursos são tratados "como práticas que formam sistematicamente os objetos de que falam" (Ibid., p.55), o que possibilita pensar na produção e fabricação de verdades sobre as coisas e os sujeitos.

As políticas de inclusão investem na família de pessoas com deficiência para que possam regular suas condutas, vigiar e controlar o meio familiar, buscando com 
isso prevenir e administrar os riscos sociais. Ao se considerarem determinadas condutas como adequadas para que a inclusão aconteça, procura-se desenvolver no âmbito familiar alguns comportamentos que venham garantir a seguridade da população. Nesse sentido, responsabilizando-se a família pelo futuro dos filhos com deficiência, criam-se as condiçôes de possibilidade para o investimento das políticas de inclusão, posicionando como necessário à família:

\begin{abstract}
construir padróes cooperativos e coletivos de enfrentamento dos sentimentos, de análise das necessidades de cada membro e do grupo como um todo, de tomada de decisóes, de busca dos recursos e serviços que entende necessários para seu bem-estar e uma vida de boa qualidade (BRASIL, 2004, p.7).
\end{abstract}

É possível perceber, nesse trecho, que a família é chamada a assumir a responsabilidade pelo bem-estar e a qualidade de vida de todos os seus membros. Penso também que, a partir do que foi dito, há um investimento por parte do Estado no estabelecimento de estratégias que possibilitem o envolvimento de toda a família em açôes que visam à modificaçáo das condutas de seus membros. Esta mobilizaçáo da família contribui para a prevenção e gerenciamento de fatores de risco, já que a utilização de recursos e serviços organizados pelo Estado contribuirá para criar situaçóes que contenham a ocorrência de problemas que possam afetar a família, comprometendo a ordem social.

Dessa maneira, para o gerenciamento do risco, diferentes serviços passam a incidir sobre a família de pessoas com deficiência, disponibilizando-lhes orientações que possam evitar perigos e ameaças. No conjunto discursivo dos materiais, isso pode ser verificado quando se considera que "é essencial que se invista na orientaçáo e no apoio à família [...]" (BRASIL, 2004, p.7). Para tanto, "cabe ao poder público garantir um sistema de serviços que promova a saúde física e mental das famílias, em geral" (Ibid., p.8), o que possibilitaria uma economia política de poder, já que, orientando a família sobre diferentes questóes, esses serviços possibilitam gerenciar ao mesmo tempo os sujeitos com deficiência, seus pais e irmãos, entre outros membros da família e das comunidades onde vivem. Penso que os serviços colocados em movimento pelas políticas de inclusão operam como estratégias de vigilância e controle do meio familiar que potencializam a prevenção do risco social, possibilitando que a família ocupe posiçôes que se configuram como mais seguras para a sociedade.

O importante é que a família apresente alguns comportamentos
por meio dos quais pode ser regulada de determinado modo. Para
regular a família, é preciso que ela mantenha-se unida, zelando
pela educaçáo, saúde e emprego de todos os seus membros e
seguindo algumas orientaçóes fornecidas pelos programas de in-
tervençáo para náo se expor aos fatores de risco (TRAVERSINI,
2003,129 ).

Ao narrar as famílias de pessoas com deficiência como aquelas que devem ser "autogestoras", os discursos da inclusão posicionam a oferta de um sistema de serviços como garantia de formação e constituição dessas famílias. Desse modo, cabe aos municípios "investir na identificação das necessidades da população, para planejar os 
seus serviços e atendimentos" (BRASIL, 2004, p.9), o que configura o investimento num saber para classificar, categorizar as famílias. Percebo com isso que os serviços de saúde, orientação e educação engendrados pelas políticas de inclusão e voltados à família dos sujeitos com deficiência se colocam como estratégias para gerenciá-la. Nos discursos da inclusão, essa família possui membros em situação de risco.

Nessa rede, os municípios são chamados a colaborar na constituição da família de pessoas com deficiência como alvo de vigilância. Para tanto, formas de estatística aparecem como técnicas de produção de saberes que levam à necessidade de investimentos específicos como, por exemplo, os indicadores que buscam orientar tanto as famílias quanto os gestores sobre quais serviços devem ser acionados para tornar o sistema "eficaz", sinônimo, nesse caso, de inclusivo. É uma forma de conhecer para governar. Nesse jogo, visualizamos o investimento de um biopoder, ou seja, conhecer e gerenciar a vida das populaçóes. Tal operaçáo em movimento é visível no trecho a seguir:

Cabe ao município, ao realizar o diagnóstico da demanda em sua população, orientar as instituiçóes quanto às necessidades nelas presentes e estimular o desenvolvimento de outros serviços necessários como, por exemplo, promover ciclos de palestras, sessóes de vídeos com profissionais especializados para informar, orientar e esclarecer a comunidade escolar sobre a prevenção e causas das deficiências. Para tanto, faz-se necessária a implementação de um sistema de informaçôes interinstitucionais que possibilite fornecer dados sobre a rede de serviços sociais, facilitando o acesso da comunidade a estas informaçôes, oferecendo-lhes maior autonomia (BRASIL, 2004, p.15).

Considerando a aplicação do poder que busca intervir na vida, ou melhor, "para aumentar a vida, para controlar seus acidentes, suas eventualidades, suas deficiências" (FOUCAULT, 1999, p.295), entendo que os indicadores fabricados pelo Governo se configuram como ferramentas produtivas para a construção de conhecimentos sobre a vida da população e para intervenção nos fenômenos que colocam em risco não só as famílias, mas a população com um todo. Segundo Arnold (2006), quando são criados sistemas de vigilância e controle sobre determinados sujeitos, estes se tornam alvos da estatística, possibilitando que o risco seja produzido e gerenciado.

Cabe considerar que esses indicadores são utilizados pelos órgãos oficiais no sentido de produzir estimativas estatísticas dos municípios brasileiros com relação ao atendimento do objetivo de garantir um sistema de serviços às famílias de pessoas com deficiência. Cito alguns desses indicadores apresentados no material Educação Inclusiva: a família (BRASIL, 2004), buscando dar visibilidade a essas questôes:

Sistema organizado e ágil de atenção pré-natal a gestantes e seus familiares (BRASIL, 2004, p.8).

Sistema eficiente de informaçóes sobre os serviços de saúde disponíveis para as gestantes e seus familiares (Ibid., p.9).

Serviços sistemáticos de suporte para a mãe após o parto (Ibid., p.11). 
Atendimento Educacional especializado para bebês com necessidades educacionais especiais (Ibid., p.12).

Educação Infantil Inclusiva (Ibid., p.12).

Serviços de avaliação e atendimento de crianças e adolescentes com necessidades educacionais especiais (Ibid., p.13).

Serviço de atendimento às famílias que têm filhos com necessidades especiais (Ibid., p.13) ${ }^{2}$.

É possível perceber nos fragmentos que a ingerência da vida da população tem início antes mesmo do nascimento, através das ações de saúde à gestante, estendendo-se a todas as etapas de desenvolvimento do sujeito - e não só o sujeito é mantido sob controle, mas também sua família. O que quero dizer aproxima-se da análise empreendida por Traversini (2003), que, ao olhar para os discursos do Programa Alfabetização Solidária (PAS), compreende que há uma ação direta e indireta sobre a família para efetivar o controle das zonas de risco. A autora diz:

Age-se diretamente por meio de programas de erradicação do analfabetismo, de incentivo à permanência das crianças na escola, de continuidade da escolarização, de qualificação profissional, de geração de renda, de campanhas de prevenção de doenças, etc. Agese sobre a família de modo indireto, incitando-se a participação de todos os seus membros nos programas oferecidos, visando a desenvolver sua auto-responsabilizaçáo pela melhoria de sua qualidade de vida, pelo aumento da produtividade e pela manutenção de uma vida saudável (TRAVERSINI, 2003, p.132).

Açóes desse caráter, colocadas em funcionamento por meio de programas e serviços públicos, posicionam a família de pessoas com deficiência como alvo de intervenção de diferentes expertises, que num exercício de poder-saber investem sobre seus membros, buscando normalizá-los. Para Arnold (2006, p.150), "é no espaço do risco social que os especialistas e serviços de apoio aparecem ocupando lugar. Um espaço em que a produção de estratégias de prevenção se torna necessária quando a política se volta para o controle do risco". Dessa maneira, especialistas de diversas áreas de saber acabam por ocupar o lugar de quem deve e pode orientar as famílias de pessoas com deficiência sobre como conduzir "melhor" suas açóes.

Para os discursos da inclusão, "é importante que os profissionais desenvolvam relaçóes interpessoais saudáveis e respeitosas, garantindo-se assim maior eficiência no alcance de seus objetivos" (BRASIL, 2004, p.7). Para tanto, estes experts, utilizandose de conhecimentos científicos, são legitimados para investir sobre a família a fim de que esta assuma o cuidado de todos os seus membros, buscando garantir que a inclusão dos filhos com deficiência se torne possível.

Assim, numa sociedade inclusiva, a relação dos profissionais com os familiares deve ser de cooperação, juntos na direção do atendimento às necessidades especiais da criança. Os objetivos a serem alcançados e as decisóes a serem tomadas devem ser discutidos entre todos os envolvidos. Cabe aos profissionais esclarecer todos 
os passos dos atendimentos que vão ser realizados e o que vai acontecer. A decisão dos familiares deve estar baseada em informações dadas por esses profissionais (BRASIL, 2006, p.7).

Os pais devem fazer uma aliança com os profissionais de reabilitação, que são os médicos, os terapeutas ocupacionais, os fisioterapeutas, entre outros, ainda que isso não seja uma tarefa fácil, no início (BRASIL, 2006, p.23).

A produção da família de pessoas com deficiência como alvo dos experts nas políticas de inclusão possibilita pensar na naturalização da família como espaço indispensável de intervenção e responsabilidade sobre os filhos com deficiência. Os discursos das políticas de inclusão, enfatizando a necessária aliança família/profissionais, inscrevem a família numa lógica em que os saberes dos especialistas são tomados como verdades absolutas e inquestionáveis, produzindo um processo de regulação também da família.

Nos documentos analisados, considera-se que "os profissionais devem valorizar o saber dos pais e incentivar pequenas iniciativas. Esses diálogos e as trocas de informação aproximam a família e os especialistas e assim fica mais fácil alcançar os objetivos traçados" (BRASIL, 2006, p.24). Visualiza-se, nessa conjuntura, a circulação de alguns significados sobre a possibilidade de a família de pessoas com deficiência funcionar como uma extensão da clínica. Ao receber "recomendaçôes" fundamentadas em saberes científicos, a família passa a operar como um mecanismo de vigilância também em casa.

Ações como, "desenvolver cursos e campanhas de orientações sobre causas e conseqüências das deficiências" (BRASIL, 2004, p.10); disponibilizar "serviços de suporte psicológico" (BRASIL, 2004, p.11); "Programas de Saúde da Família e de Agentes Comunitários [...]: grupos de gestantes, grupos de pais, grupos de igrejas, grupos de jovens, dentre outros" (BRASIL, 2004, p.11-12); "Trabalhos em grupo" (BRASIL, 2004, p.13); "suporte terapêutico" (BRASIL, 2004, p.14); "Grupos de pais e de irmãos” (BRASIL, 2004, p.14), também são colocadas em funcionamento para prevenir a ocorrência de fatores de risco, bem como para gerenciar o risco quando este vier a acontecer.

Quando a família é chamada a participar de outros grupos, considera-se que ela terá condições de melhor agir com relação aos filhos com deficiência. Parece ser mais eficiente colocar as famílias em relaçáo, em grupos, pois assim todos são capturados. A família deve estar sempre em interação, incluída em diferentes espaços, nunca isolada. Na lógica inclusiva, é imperioso que todos se mantenham conectados, numa espécie de rede de parceria da qual todos devem fazer parte. Então, a inclusão não se efetua somente na escola; a família também é chamada a se "incluir" em espaços comuns. Com isso, a família é mais bem vigiada e regulada.

A parceria entre a família de pessoas com deficiência e a inclusão acaba sendo legitimada nos discursos aqui analisados. Manter a família em interação possibilita dotá-la de saberes, o que a posiciona também como agente das políticas de inclusão. A partir da leitura e releitura dos documentos, pude perceber que a família vem sendo 
produzida por diferentes discursos e legitimada por práticas diversas que ora a inscrevem como alvo das políticas de inclusão - possibilitando a vigilância e controle do meio familiar pela operacionalização das estratégias e mecanismos que busquei tratar nesse texto -, ora como agente dessas políticas.

\section{Referências}

ARNOLD, D. K. Dificuldade de aprendizagem: o estado de corrigibilidade na escola para todos. 2006. Dissertação (Mestrado em Educação) - Universidade do Vale do Rio dos Sinos: São Leopoldo, 2006.

BAUMAN, Z. Comunidade: a busca por segurança no mundo atual. Tradução: Plínio Dentzien. Rio de Janeiro: Jorge Zahar, 2003.

BRASIL. Educaçâo inclusiva: a família. 1. ed. Brasília: Ministério da Educação, Secretaria de Educação Especial, 2004. (Série: Educação Inclusiva; 4)

BRASIL. A hora e a vez da família em uma sociedade inclusiva. Brasília: Ministério da Educação, Secretaria de Educação Especial, 2006.

DONZELOT, J. A polícia das famílias. Tradução: ALBUQUERQUE, M. T. da C. 3. ed. Rio de Janeiro: Graal, 2001.

FOUCAULT, M. Em defesa da sociedade: curso no Collège de France (1975-1976). Tradução: Maria Ermantina Galvão. São Paulo: Martins Fontes, 1999.

FOUCAULT, M. Os anormais: curso no Collège de France (1974-1975). Tradução: Eduardo Brandão. São Paulo: Martins Fontes, 2001.

FOUCAULT, M. Arqueologia do saber. Tradução: Luiz Felipe Baeta Neves. 7. ed. Rio de Janeiro: Forense Universitária, 2008.

FOUCAULT, M. Vigiar e punir: nascimento da prisão. Tradução: Raquel Ramalhante. 35. ed. Petrópolis: Vozes, 2008a.

SILVA, T. T. da. Teoria cultural e educaçáo: um vocabulário crítico. Belo Horizonte: Autêntica, 2000.

TRAVERSINI, C. S. Programa Alfabetizaçáo Solidária: o governamento de todos e de cada um. 2003. Tese (Doutorado em Educaçáo) - Universidade Federal do Rio Grande do Sul: Porto Alegre, 2003.

\section{Notas}

${ }^{1}$ Entre eles, é possível citar: o abandono, característico das sociedades primitivas; a prática do infanticídio, comum nas sociedades espartanas da época clássica; a estigmatização e segregaçáo, características da Idade Média; as exclusôes, que marcaram o século XVII no período da Revolução Industrial, etc.

${ }^{2}$ Esses excertos estão grifados em negrito no material original, contudo, opto por utilizar a formatação padrão utilizada no decorrer do texto quando săo citados os documentos.

${ }^{3}$ Foucault (2008a, p.27), ao tratar das relaçôes de poder-saber, esclarece que "temos antes que admitir que o poder produz saber (e não simplesmente favorecendo-o porque o serve ou aplicando-o porque é útil); que poder e saber estão diretamente implicados; que nâo há relaçấo de poder sem constituiçấo correlata de um campo de saber, nem saber que suponha e não constitua ao mesmo tempo relaçóes de poder".

\section{Correspondência}

Priscila Turchiello - Instituto Federal Farroupilha, Campus Jaguari. BR 287, KM 360, Estrada do Chapadão, s/nº, Chapadão. CEP: 97760000. Jaguari, Rio Grande do Sul, Brasil.

E-mail: priscilaturchiello@gmail.com

Recebido em 26 de setembro de 2016

Aprovado em 28 de setembro de 2016 
